\title{
Behavior of Lap Splice Reinforcement Bars in Light weight Concrete
}

\author{
Waleed.A.Ali ${ }^{1}$, Rana Elnakeeb ${ }^{2}$ \\ 1,2 Civil Department, Faculty of Engineering at Mataria' Helwan University \\ ${ }^{1,2}$ Cairo, Egypt \\ ${ }^{1}$ Waleed_abdallah@m-eng.helwan.edu.eg \\ ${ }^{2}$ rana.elnakeeb.91@gmail.com
}

\begin{abstract}
Using the lightweight concrete (LWC) in the RC structures has become widespread because of its certain effect on reducing the structures self-weight. Recently Expanded Polystyrene (EPS) beads had used as a replacement of natural aggregate and one of many ways to produce $L W C$, that is due to its low density. By varying the EPS content within the mix, it's possible to obtain a structural EPS concrete characterized by perfect abilities of thermal as well as acoustic insulation and chemical resistance. Forces transfer between spliced bars through the surrounding concrete, therefore studying the bond between concrete and reinforcing spliced bars is necessary in order to investigate the efficiency of splicing. The objective of this research is to investigate the behavior of lapped splices of reinforcement bars within structural EPS lightweight concrete beams. The studied parameters in this research were the presence of splicing, bar size, spacing between stirrups, spliced length and the concrete cover. Deflection, cracking pattern, failure mode and longitudinal steel strain are presented and discussed in this study according to the Egyptian and American codes. Lightweight concrete exhibits good performance with splicing efficiency, which is directly proportional to the spliced length and the depth of the concrete cover, however inversely proportional to the stirrups spacing and spliced bar size.
\end{abstract}

Keywords: Bond; Concrete; Lap splice; LWC; Expanded Polystyrene

\section{INTRODUCTION}

Lightweight concrete (LWC) is a devised type of concrete, which contains air in its composition and has a low density. It is a widely used in buildings as masonry blocks, wall panels, roof decks and precast concrete units. The most common type of lightweight concrete is produced by replacing the conventional aggregate in the mix with lightweight aggregate, natural or artificial type, either partial or full replacement. This depending on the required density, which affect physical properties and strength as reported by [1] and [2]. The lightweight aggregates are characterized by higher porosity, lower density and a consequent lower strength than traditional aggregates as indicated by [3]. Topcu and Uygunoglu [4] studied the LWC and found that, its behavior depends upon the physical, chemical properties of its components and the interaction between them. They also concluded that the properties of LWC considered are thermal insulation, fire protection, durability, water absorption, and acoustic properties. EPS concrete exhibits greater fire endurance than traditional concrete, according to the theory presented by Tan [5] which states that under high temperatures, the heat transfer through of porous materials, like concrete, is an inverse function of the number of air-solid interfaces traversed. ACI committee (408R-03) had reported that the affective bond stresses are constant over the spliced length of the bar and the relationship between the splice length and the splice strength is linear. While Canbay and Frosch [6] reported that this assumption is more accurate for the short lap splices than the longer ones and the realistic relationship is not linear, but the splice strength is proportional to the square root of the ratio of the splice length to the diameter of the spliced bar $(\sqrt{ }(\mathrm{ld} / \mathrm{db}))$. The ACI committee (408R-03) states that, the bond strength increases with increasing concrete cover, but this relationship, is not linear so the extra concrete cover does not provide an additional protection against excessive surface crack width or improve the bond performance. Also states that, the bond is always greater for smaller bar diameters than for larger ones, so it is preferable to use a larger number of small bars than a smaller number of large bars provided that the spacing between the bars doesn't become so small to the extent that decreases the bond strength. Transverse reinforcement by closely spaced stirrups can enable better bond forces to be transmitted, confine the spliced bars, increase the required failure load, prevent the forming of the splitting cracks, change the mode of member's failure from splitting to pull-out failure and limit the propagation of the splitting cracks by enabling friction to be transferred along the cracks [6] and [7]. Splice plays an important role of transferring the forces between the spliced bars through the surrounding concrete by steel bars-concrete interfacial bond. Few studies concerns with the bond behaviour between the steel bars and LWC, so this present study aims to evaluate the behavior of lapped splices of reinforcement bars within structural EPS. 


\section{EXPERIMENTAL WORK}

Ten specimens of EPS reinforced concrete beam with 25 MPa compressive strength, $1800 \mathrm{~kg} / \mathrm{m} 3$ density and cross section $200 \times 300 \mathrm{~mm}$ with $2000 \mathrm{~mm}$ span were tested in this study, in addition to two comparable normal weight concrete beams with the same concrete dimensions and compressive strength were constructed. Beams had three varied bar sizes, stirrups spacing, splicing lengths and depths of lower concrete covers. There were two referenced non-spliced beams, one for each concrete type. Table (I) and Fig. (1) show the reinforcement details for the testing beams.

TABLE I. Details of Tested Beams

\begin{tabular}{|c|c|c|c|c|c|c|c|}
\hline \multirow{2}{*}{$\begin{array}{l}\text { Beam } \\
\text { Code }\end{array}$} & \multirow{2}{*}{$\begin{array}{c}\text { Concrete } \\
\text { Type }\end{array}$} & \multirow{2}{*}{$\begin{array}{c}\text { Top } \\
\text { Reinforcement }\end{array}$} & \multicolumn{2}{|c|}{$\begin{array}{c}\text { Bottom } \\
\text { Reinforcement }\end{array}$} & \multirow{2}{*}{$\begin{array}{l}\text { Spliced } \\
\text { Length } \\
\mathrm{mm}\end{array}$} & \multirow{2}{*}{ Stirrups } & \multirow{2}{*}{$\begin{array}{c}\text { Lower } \\
\text { Cover } \\
\text { mm }\end{array}$} \\
\hline & & & straight & spliced & & & \\
\hline AN & NWC & \multirow{12}{*}{ 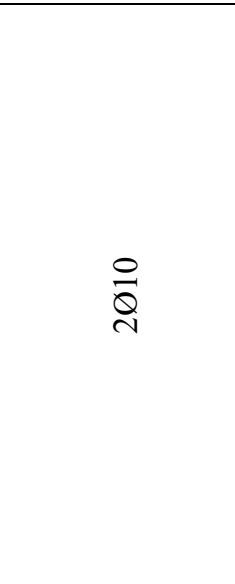 } & $2 \varnothing 10$ & -- & \multirow{2}{*}{-- } & \multirow{6}{*}{$7 \varnothing 8 / \mathrm{m}^{\prime}$} & \multirow{10}{*}{20} \\
\hline $\mathrm{AL}$ & LWC & & $2 \varnothing 10$ & -- & & & \\
\hline $\mathrm{BN}$ & NWC & & -- & \multirow{2}{*}{$2 \varnothing 10$} & \multirow{2}{*}{550} & & \\
\hline $\mathrm{BL}$ & \multirow{9}{*}{ LWC } & & -- & & & & \\
\hline $\mathrm{C}$ & & & -- & $2 \varnothing 16$ & 880 & & \\
\hline $\mathrm{D}$ & & & -- & $2 \varnothing 22$ & 1210 & & \\
\hline $\mathrm{E}$ & & & -- & \multirow{6}{*}{$2 \varnothing 10$} & \multirow{2}{*}{550} & $10 \varnothing 8$ & \\
\hline $\mathrm{F}$ & & & -- & & & $5 \varnothing 8 / \mathrm{m}^{\prime}$ & \\
\hline $\mathrm{G}$ & & & -- & & 350 & \multirow{4}{*}{ 7Ø8/m' } & \\
\hline $\mathrm{H}$ & & & -- & & 450 & & \\
\hline $\mathrm{I}$ & & & -- & & \multirow{2}{*}{550} & & 10 \\
\hline $\mathrm{J}$ & & & -- & & & & 40 \\
\hline
\end{tabular}

$\mathbf{A} \rightarrow$ Non-spliced beam. $\quad \mathbf{B} \rightarrow$ Spliced beam. $\quad \mathbf{N} \rightarrow$ NWC. $\quad \mathbf{L} \rightarrow$ LWC
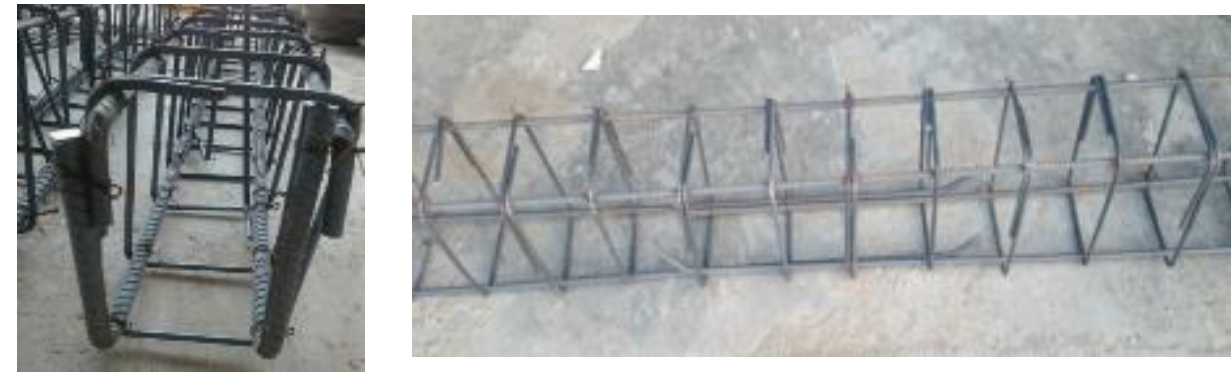

Fig. (1): Reinforcement details

A. Structural Details

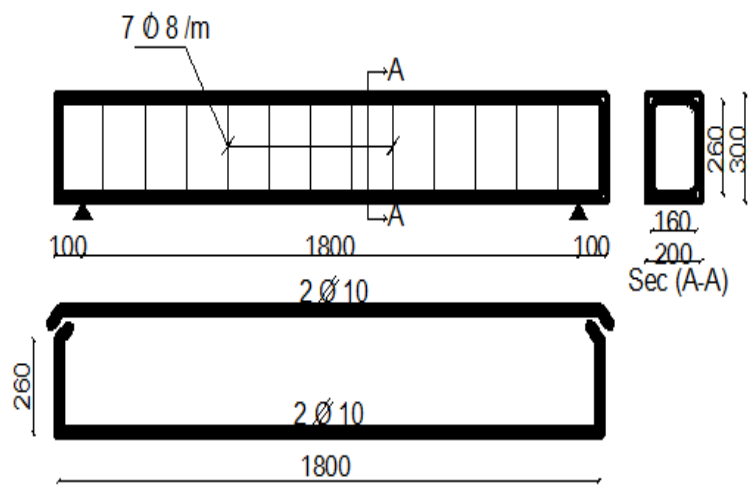

Fig. (2): Detailing of the non-spliced NWC (AN).

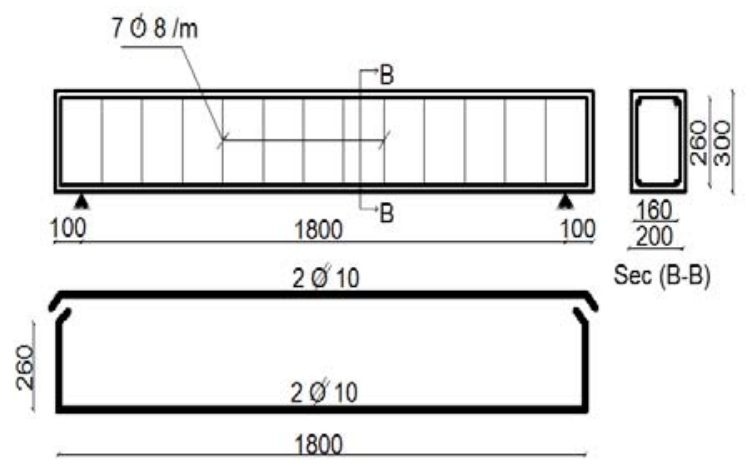

Fig. (3): Detailing of the non-spliced LWC (AL). 
With bar size $(\varnothing=10 \mathrm{~mm}),($ Stirrups spacing $=150 \mathrm{~mm})$ and (bottom cover $=20 \mathrm{~mm})$.

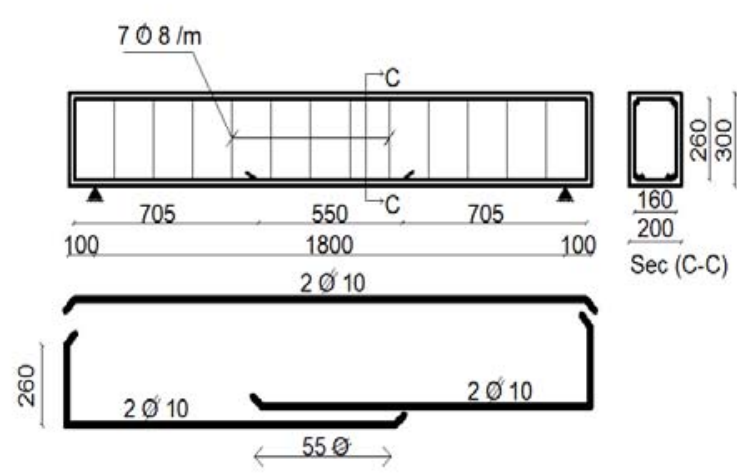

Fig. (4): Detailing of the spliced NWC beam (BN).

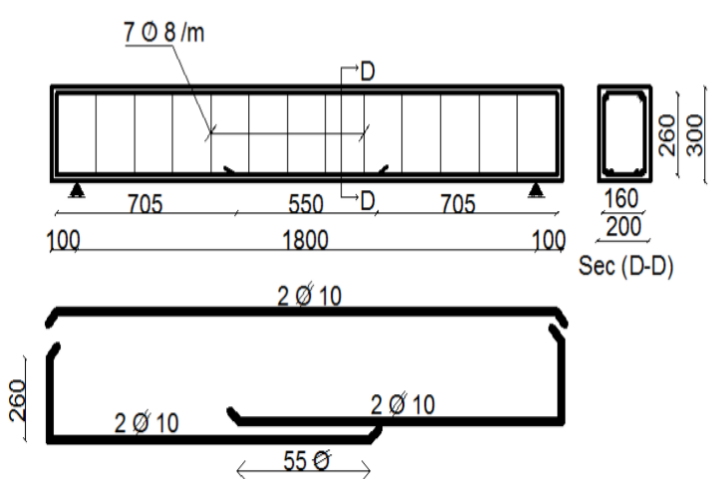

Fig. (5): Detailing of the spliced LWC beam (BL)

With bar size $(\varnothing=10 \mathrm{~mm})$, (Stirrups spacing $=150 \mathrm{~mm})$, (bottom cover $=20 \mathrm{~mm})$ and $(\mathrm{L}$ splice $=55 \varnothing)$.

Notes, splicing length 55Ø as indicated in ECP 203-2018 Table (4 - 9) Page (4-40)

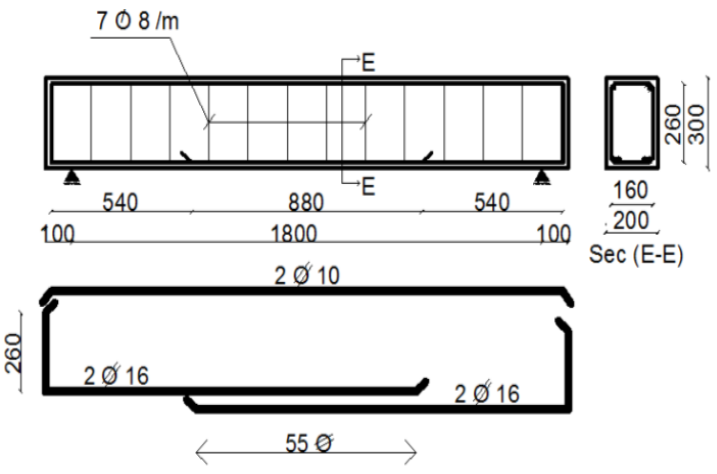

Fig. (6): Detailing of the spliced LWC beam (C)

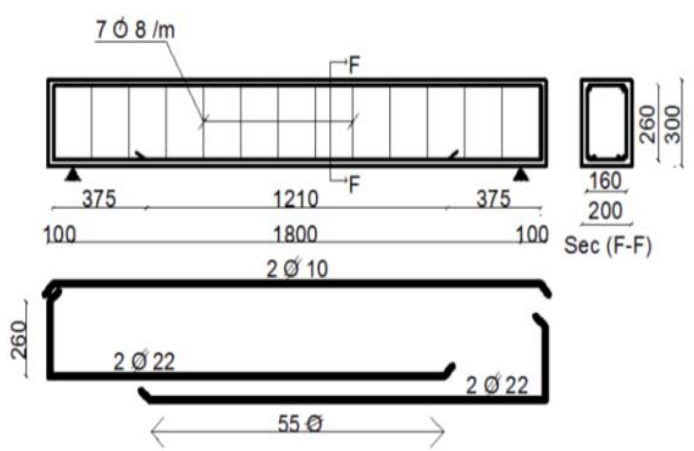

Fig. (7): Detailing of the spliced LWC beam (D)

With bar size (Stirrups spacing $=150 \mathrm{~mm})$, (bottom cover $=20 \mathrm{~mm})(\mathrm{L}$ splice $=55 \varnothing)$ and Bar size $(\varnothing=16 \mathrm{~mm})$. Bar size $(\varnothing=22 \mathrm{~mm})$.

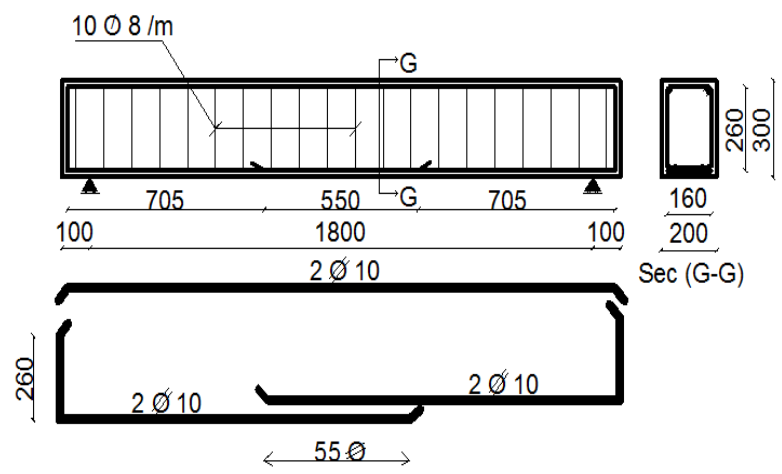

Fig. (8): Detailing of the spliced LWC beam (E)

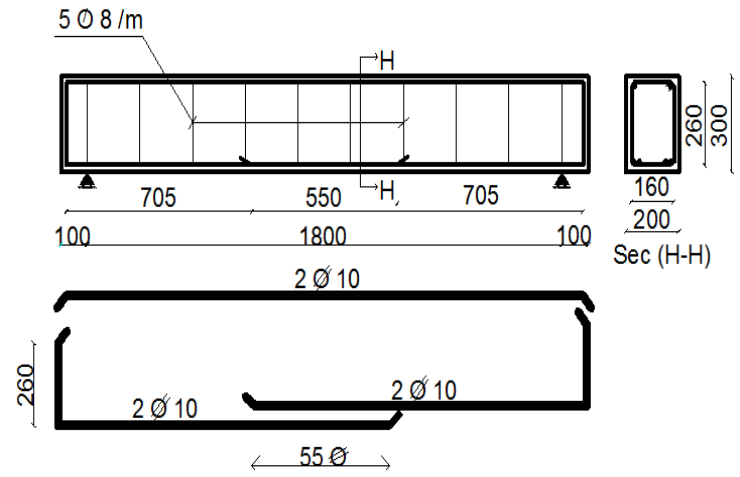

Fig. (9): Detailing of the spliced LWC beam (F) 
With bar size $(\varnothing=10 \mathrm{~mm}),($ bottom cover $=10 \mathrm{~mm}),($ Splice $=55 \varnothing)$ and. (Stirrups spacing $=100 \mathrm{~mm})$. (Stirrups spacing $=200 \mathrm{~mm}$ )

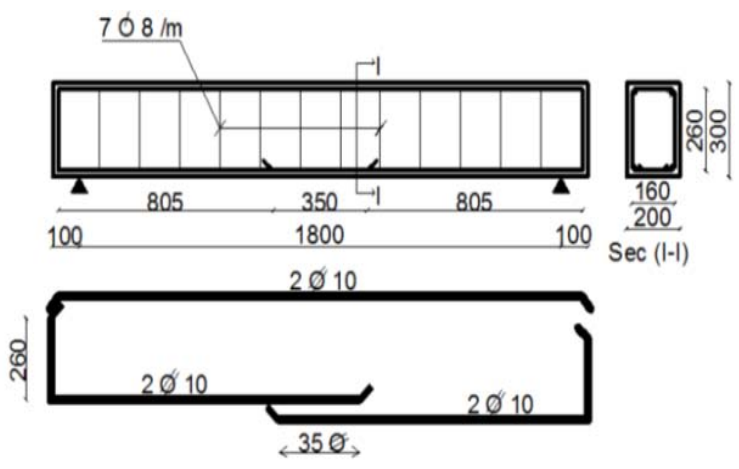

Fig. (10): Detailing of the spliced LWC beam (G)

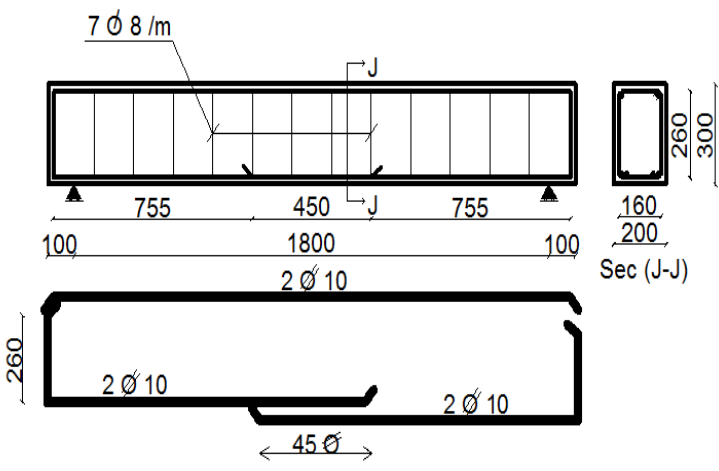

Fig. (11): Detailing of the spliced LWC beam (H)

With bar size $(\varnothing=10 \mathrm{~mm})$, (Stirrups spacing $=150 \mathrm{~mm})$, (bottom cover $=20 \mathrm{~mm})$ and $($ Splice $=35 \varnothing)($ Splice $=$ $45 \varnothing)$.

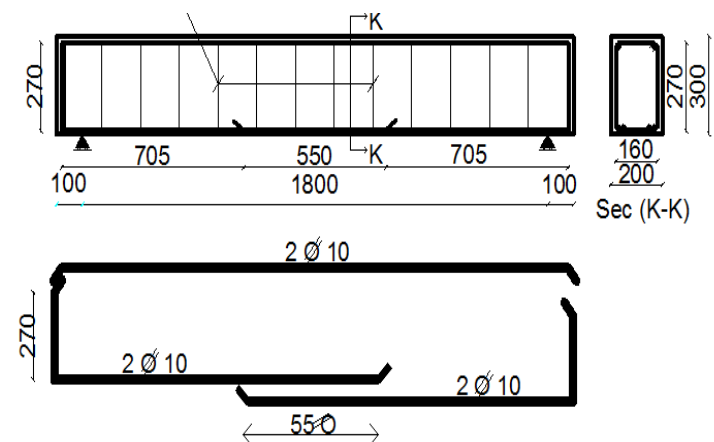

Fig. (12): Detailing of the spliced LWC beam (I)

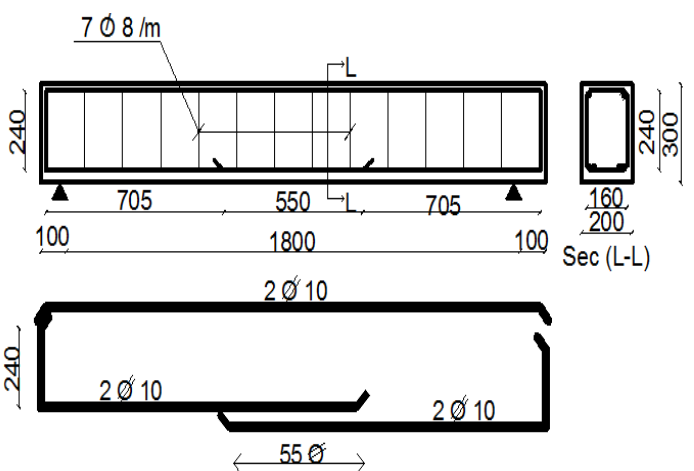

Fig. (13): Detailing of the spliced LWC beam (J)

With bar size $(\varnothing=10 \mathrm{~mm}),($ Stirrups spacing $=150 \mathrm{~mm}),(\mathrm{L}$ splice $=55 \varnothing)$. and $($ Bot. cover $=10 \mathrm{~mm})($ Bot. cover= $40 \mathrm{~mm})$.

\section{B. Mixing and Casting}

Many trial mixes were done to obtain the optimum dosage of every used material in order to achieve such two comparable mixes. After trailing and reaching the target, the final quantities required by weight for one cubic meter of fresh lightweight (LWC) and normal weight concrete (NWC) for the specimens are given in Table (II).

TABLE III. Materials quantities for normal weight and EPS lightweight concretes specimens

\begin{tabular}{|c|c|c|c|c|c|c|c|c|}
\hline Materials & $\begin{array}{l}\text { Cement } \\
\left(\mathrm{kg} / \mathrm{m}^{3}\right)\end{array}$ & $\begin{array}{c}\text { Sand } \\
\left(\mathrm{kg} / \mathrm{m}^{3}\right)\end{array}$ & $\begin{array}{c}\text { Coarse } \\
\text { aggregate } \\
\left(\mathrm{kg} / \mathrm{m}^{3}\right)\end{array}$ & $\begin{array}{c}\text { Silica } \\
\text { fume } \\
\left(\mathrm{kg} / \mathrm{m}^{3}\right)\end{array}$ & $\begin{array}{c}\text { EPS } \\
\text { beads } \\
\left(\text { liter } / \mathbf{m}^{3}\right)\end{array}$ & $\begin{array}{c}\text { Viscocrete } \\
\text { (liter } / \mathbf{m}^{3}\end{array}$ & $\begin{array}{c}\text { PP } \\
\left(\mathrm{kg} / \mathrm{m}^{3}\right)\end{array}$ & $\begin{array}{c}\text { Water } \\
\left(\text { liter } / \mathbf{m}^{3}\right)\end{array}$ \\
\hline NWC & 350 & 600 & 1200 & --- & --- & --- & --- & 180 \\
\hline LWC & 450 & 630 & 630 & 40 & 330 & 13.5 & 0.9 & 139 \\
\hline
\end{tabular}

In order to have a homogeneous mix, the dry material \{cement, silica fume, sand, coarse aggregate and the EPS beads\} was blended in the mixer then the water mixed with viscocrete and gradually added. The polypropylene fibers were added after two minutes of mechanical mixing for previous contents. Cubes of 150x150x150mm and cylinders of $150 \mathrm{~mm}$ diameter and 300mm depth were taken from each concrete mix in order to determine the compressive strength and splitting tensile strength. The specimens and the beams were cured by water sprinkling method until the date of testing. 


\section{Test Set up}

Three vertical LVDT gages were used under beams at the mid span as well as the two thirds of the span between the two supports in order to measure the vertical deflection. Also, two electrical strain gauges were fixed on the two ends of each lap splice of the longitudinal reinforcement bars of each beam in order to measure the steel strain. The beams were tested using four point bending configuration to develop a constant moment region along the middle third of the span at which the spliced length of the bars locates as shown in Fig (14). The beams were loaded in $20 \mathrm{KN}$ increments up to failure and the measurements were noted down during each loading stage.

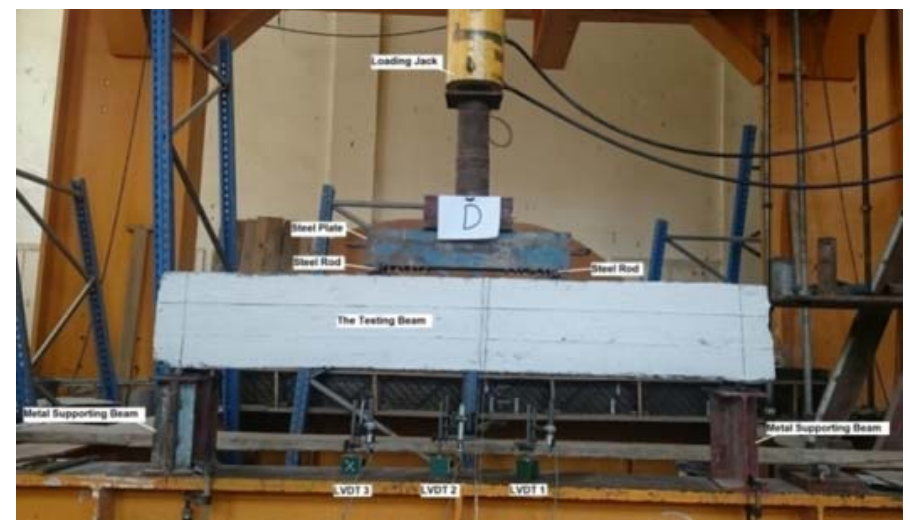

Fig. (3): Test Set-up

\section{EXPERIMENTAL RESULTS AND DISCUSSION}

Load deflection, cracking pattern, initial stiffness (Pcr/ $\Delta \mathrm{cr}$ ), Ductility (Deflection values at ultimate load (A. El-Azab (2014), ultimate and failure loads were plotted for each test specimen. The obtained results were analyzed and discussed as following.

\section{A. Effect of tension lap splicing on the behavior the LWC and NWC beams.}

Spliced and non-spliced beams were compared for both LWC and NWC in order to study the effect of tension lap splicing on the behavior of the two different concrete types. The structural details of the compared beams are shown in Fig. $(2,3,4 \& 5)$. Fig. $(15,16)$ show the load-deflection curves for the non-spliced and spliced beams respectively for the NWC and LWC. At the same load stages, LWC exhibited the values of deflection slightly greater than the NWC for both spliced and non-spliced beams. Since the reinforcement details are symmetric within the two types of beams and the ductility depends mainly on the reinforcement; the type of the used concrete did not affect the ductility, however affected the stiffness. According to the slope of the initial deflection at the linear stage of loading, NWC had an initial stiffness more than the LWC by about (107\%) and $(88 \%)$ for spliced and non-spliced beams respectively. Approaching the deflection values at the ultimate load stages for the two spliced beams reflects a better load transfer through the splices within them. It's observed from Fig. $(17,18)$ that using the splicing decreased the resulted ductility of the NWC and LWC beams by $(20.3 \%)$ and $(20.15 \%)$ respectively, while it decreased the initial stiffness by about $(7 \%)$ and $(16 \%)$ respectively; which indicated that from this study, spliced NWC beams had low reduction in the initial stiffness than LWC beams.

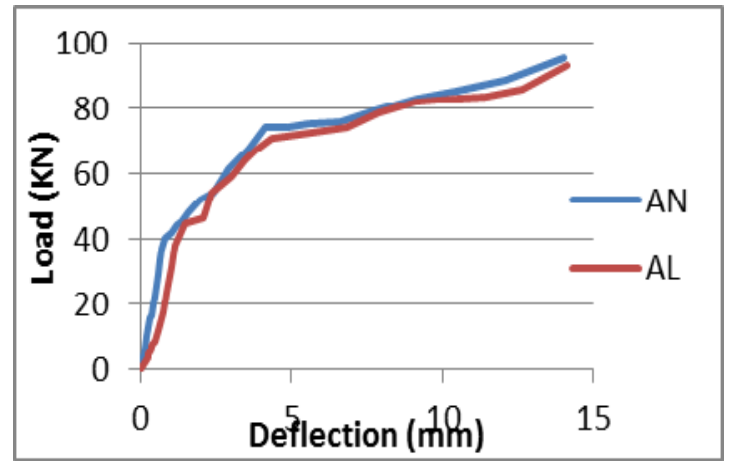

Fig. (15): Load-Deflection behavior for the non- spliced beams (AN (NWC) \& AL (LWC)).

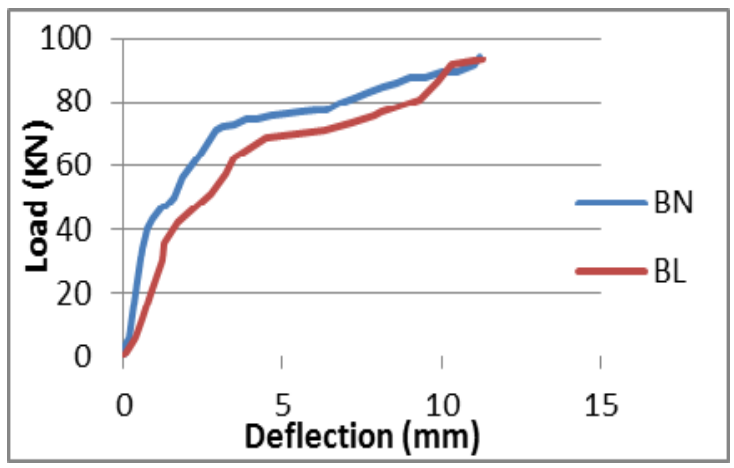

Fig. (16): Load-Deflection behavior for the spliced beams $(\mathrm{BN}(\mathrm{NWC}) \& \mathrm{AL}(\mathrm{LWC}))$ 


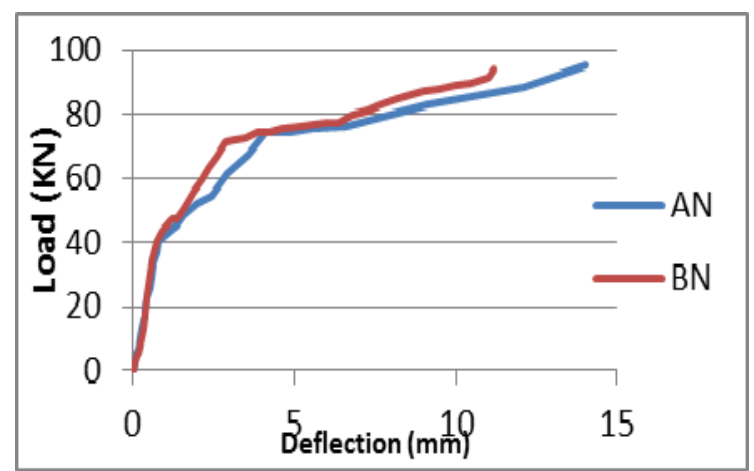

Fig. (17): Load-Deflection behavior for the NWC Non spliced and spliced beams (AN \& BN).

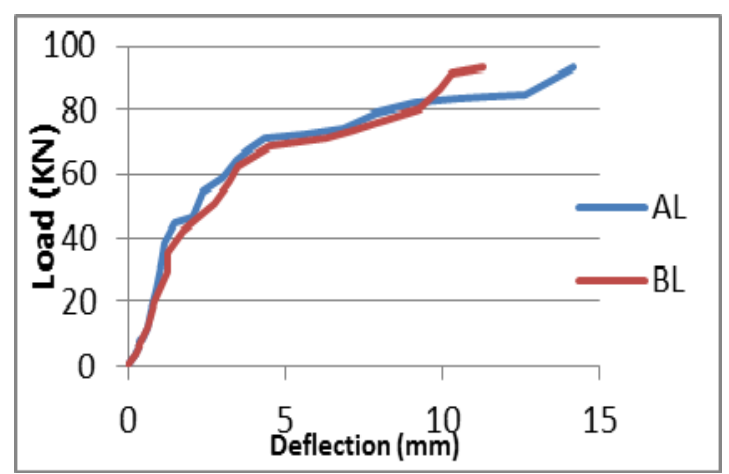

Fig. (18): Load-Deflection behavior for the LWC Non spliced and spliced beams (AL \& BL).

Fig. $(19,20)$ show crack, ultimate and failure loads. Since the strength of a beam depends on its ultimate load, minor differences were noted between NWC and the LWC strength for spliced and non-spliced beams. In this study, the splicing had an insignificant effect on the flexural strength for the NWC and LWC beams which decreased only by $(1.15 \%)$ and $(0.53 \%)$, respectively, which indicates the efficiency of the splicing length of $(550)$ according to ECP in transferring loads within the spliced beams compared with the non-spliced one.

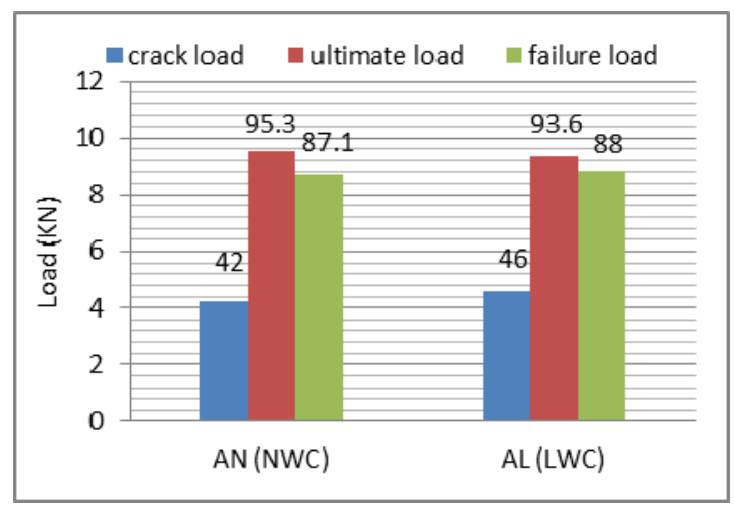

Fig. (19): Comparison of the cracking, ultimate and failure loads for the non- spliced beams (AN \& AL).

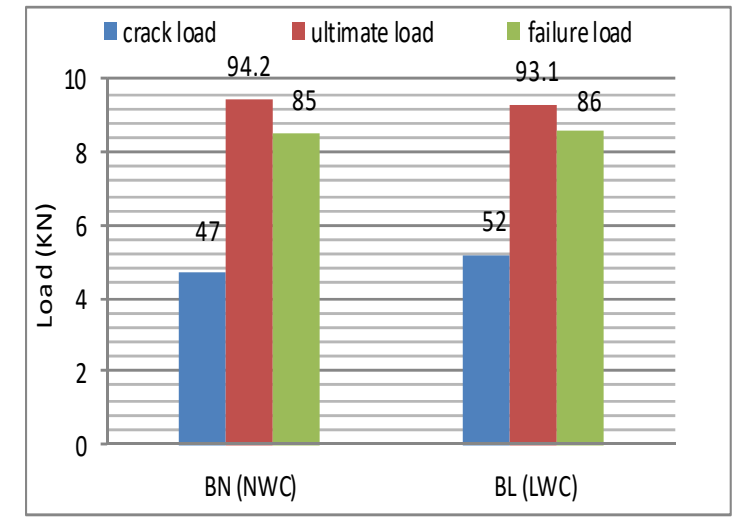

Fig. (20): Comparison of the cracking, ultimate and failure loads for the referenced spliced beams (BN \& BL)

The failure modes of the two non-spliced NWC and LWC beams (AN \& AL) were almost similar as indicated in Fig. $(21,22)$. Failure happened at the tension zone at load levels about 87 and $88 \mathrm{kN}$ respectively. The flexural cracks at the mid span expanded gradually and caused the flexural failure of the concrete, while, the non- spliced reinforcement steel bars still bear against the loads applied on each beam. Similarly, Fig.(23, 24) show that the spliced NWC and LWC beams (BN \& BL) had almost the same load of failure, which reflects that the splicing was sufficient to transfer loads within the two beams. The flexure failure occurred in both of the spliced beams outside the splicing zone. Using the splicing did not decrease considerably the failure loads for the two types. 


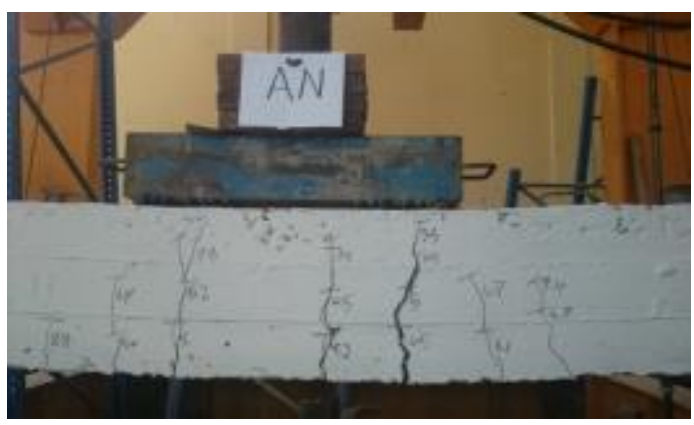

Fig. (21): Failure mode for the NWC Non-spliced beam (AN)

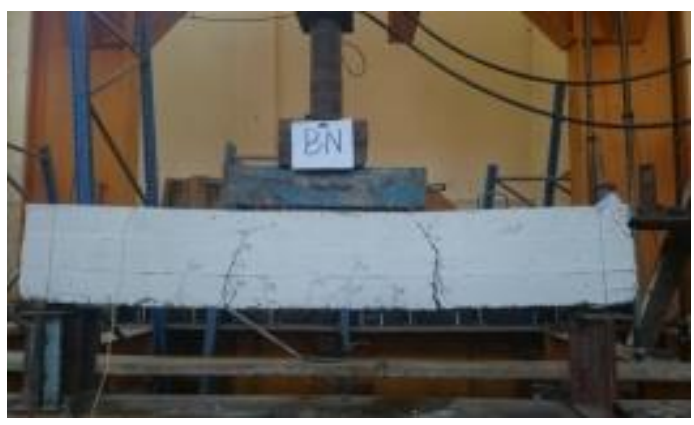

Fig. (23): Failure mode for spliced NWC beam $(\mathrm{BN})$

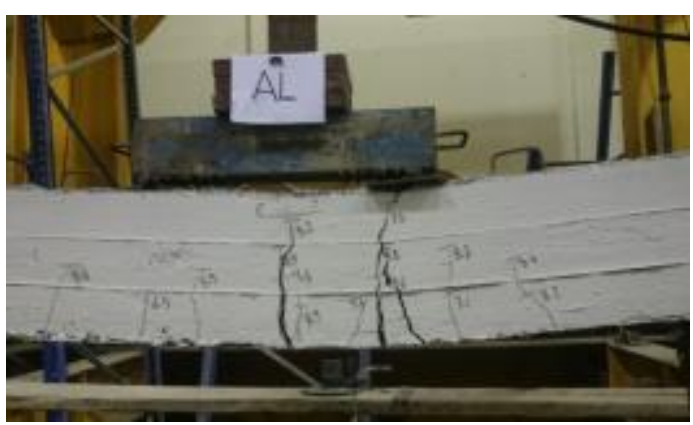

Fig. (22): Failure mode for the LWC Non-spliced beam (AL).

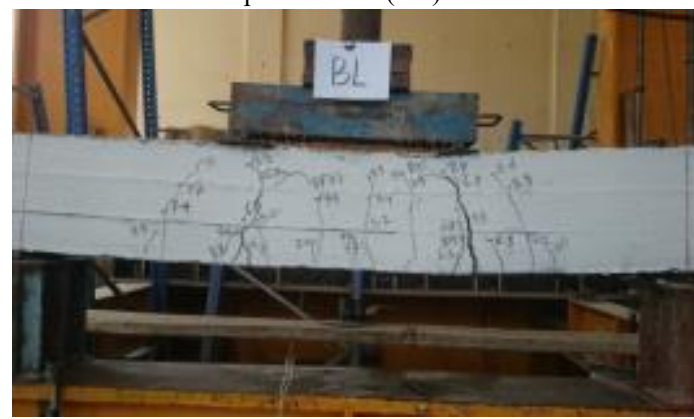

Fig. (24): Failure mode for spliced LWC beam $(\mathrm{BL})$

\section{B. Effect of the bar size on the splicing behavior}

Three spliced beams with different bar sizes $(10,16 \& 22 \mathrm{~mm})$ were compared as shown in Fig. (5\&6\&7). The load-deflection curve of the tested beams is shown in Fig. (25). It's observed that increasing the spliced bar size within a beam from $(10 \mathrm{~mm})$ to $(16 \mathrm{~mm})$ and $(22 \mathrm{~mm})$ decreased its ductility in both cases by about $(40 \%)$, however, increased the initial stiffness of the beams by $(60 \%)$ and $(151 \%)$ respectively.

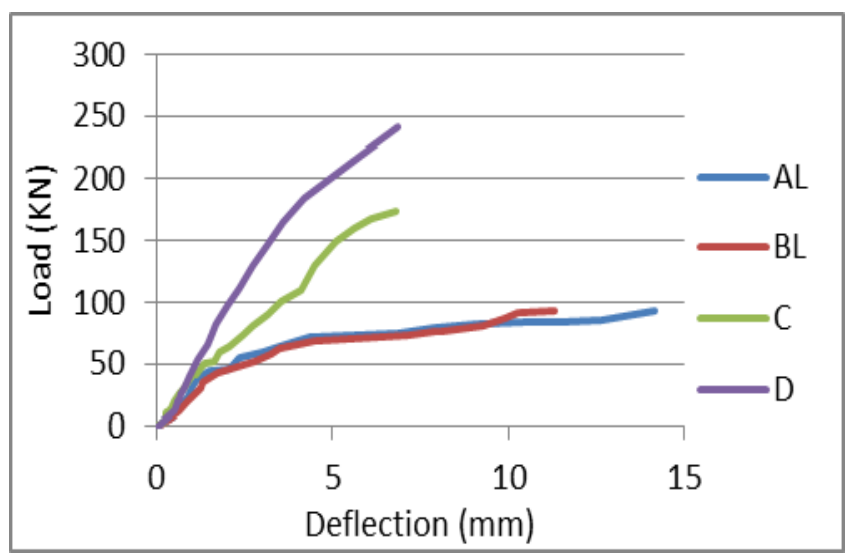

Fig. (25): Load-Deflection behavior for the spliced beams (BL, C \& D) with different sizes of spliced bars

Increasing the spliced bar size had increased the moment capacity of the beam while its shear capacity hadn't been affected. The resulted deflection of the beams at the sequent loading stages is inversely proportional to the reinforcement bar size. The failure mode was started as flexural, and then it changed to be shear-tension due to expanding the flexural-shear cracks near the ends of the splice upward as indicated from the cracking patterns and failure modes in Fig. (26, 27\& 28). The failure occurred outside the splicing zone and not far from the splice ends. The flexural strength increased by about $(86 \%)$ and $(160 \%)$ when the bar size increased from $(10 \mathrm{~mm})$ to $(16 \mathrm{~mm})$ and $(22 \mathrm{~mm})$ respectively as shown in Fig. (29). 


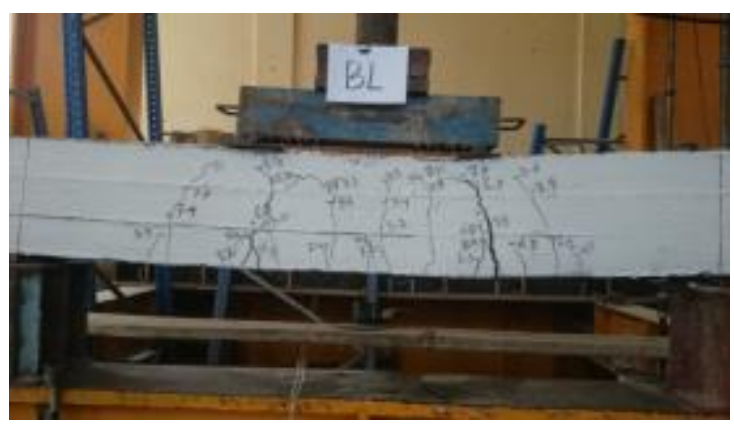

Fig. (26): Failure mode for the spliced beam BL $(\varnothing=10 \mathrm{~mm})$.

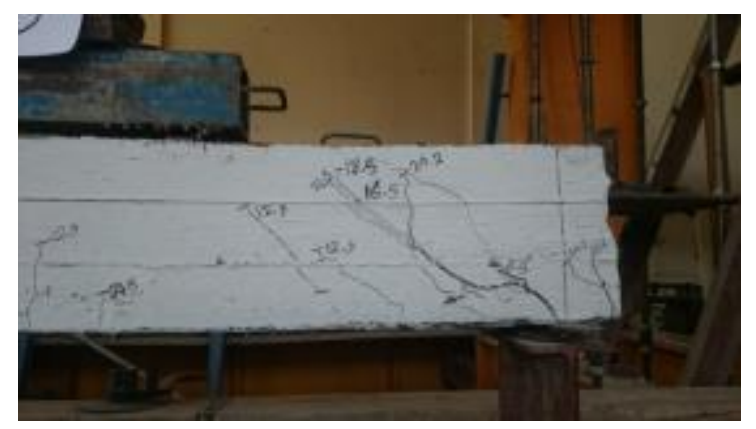

Fig. (28): Failure mode for the spliced beam D $(\varnothing=22 \mathrm{~mm})$.

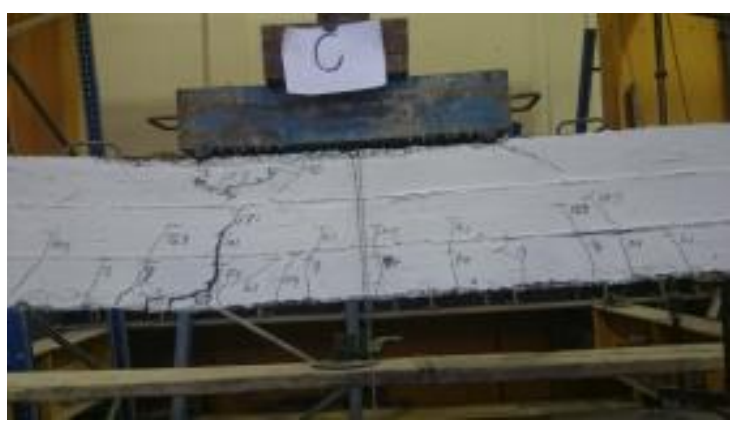

Fig. (27): Failure mode for the spliced beam $C$ $(\varnothing=16 \mathrm{~mm})$.

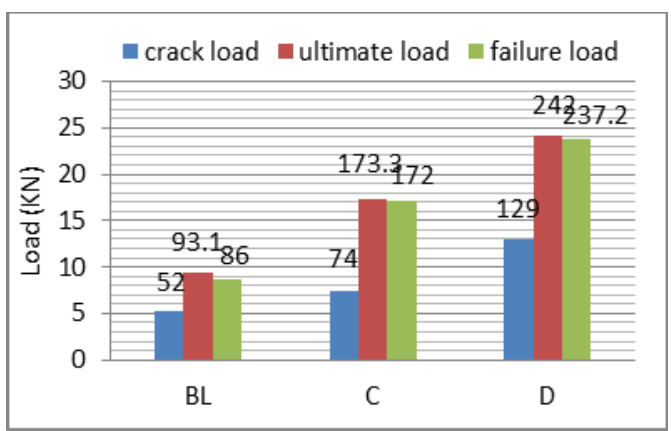

Fig. (29): Comparison of the cracking, ultimate and failure loads for the spliced beams with variable bar size (BL, $C \& D)$.

\section{Effect of stirrups spacing on the splicing behavior}

Fig. (5, 8 \& 9) show the variable stirrups spacing within the spliced beams. As the stirrups spacing reduced from $(200 \mathrm{~mm})$ to $(150 \mathrm{~mm})$ and $(100 \mathrm{~mm})$ the ductility of the beam had increased by $(4 \%)$ and $(9 \%)$ respectively, and also the initial stiffness in the linear load stage increased by about (15\%) and (44\%) respectively as shown in Fig. (30).

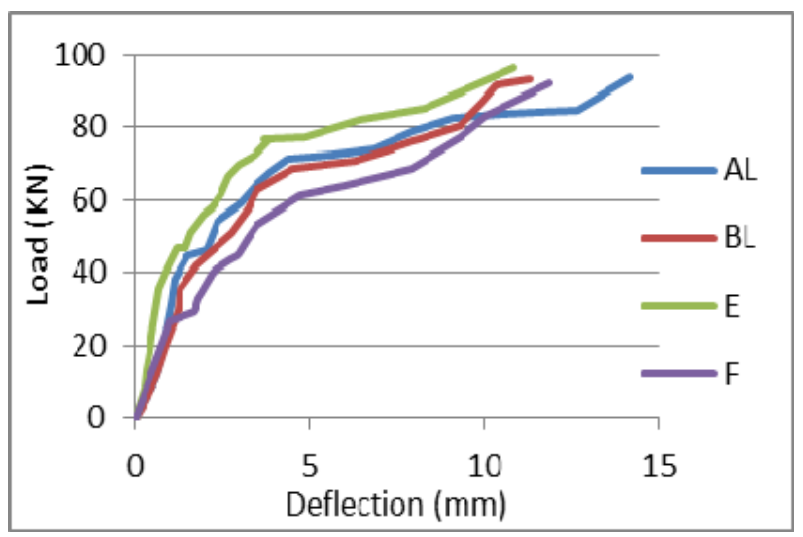

Fig. (30): Load-Deflection behavior for the spliced beams (BL, E \& F) with different stirrups spacing.

Decreasing the stirrups spacing caused a consequent decrease in the spacing between the developed cracks as shown in Fig. (31, 32 \& 33). Cracks always occur adjacent to the stirrups position; thus the applied load was distributed to numerous and closed cracks which restrained their expansion. Failure modes for the three beams were nearly the same, however the beam E (stirrups spacing $=100 \mathrm{~mm}$ ) had the narrowest crack of failure. Increasing the transverse reinforcement enhances the shear capacity of the beam, but doesn't affect considerably its flexural capacity, as decreasing the stirrups spacing from $(200 \mathrm{~mm})$ to $(150 \mathrm{~mm})$ and $(100 \mathrm{~mm})$ within a beam, increased its flexural strength only by (1.2\%) and (4.2\%) respectively respectively as shown in Fig. (34). 


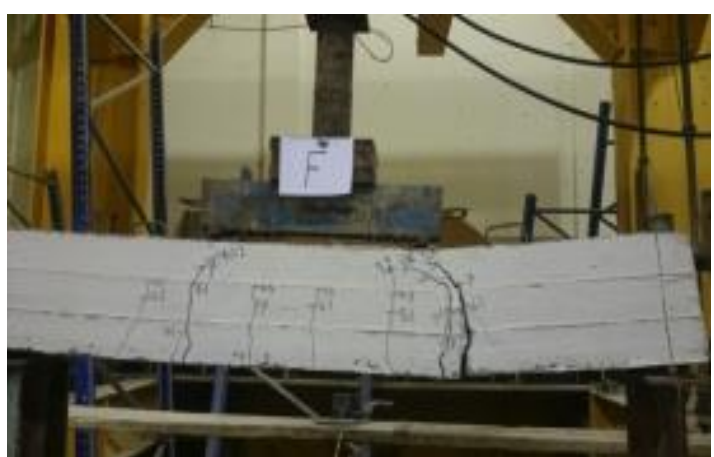

Fig. (31): Failure mode for the spliced beam $\mathrm{F}$

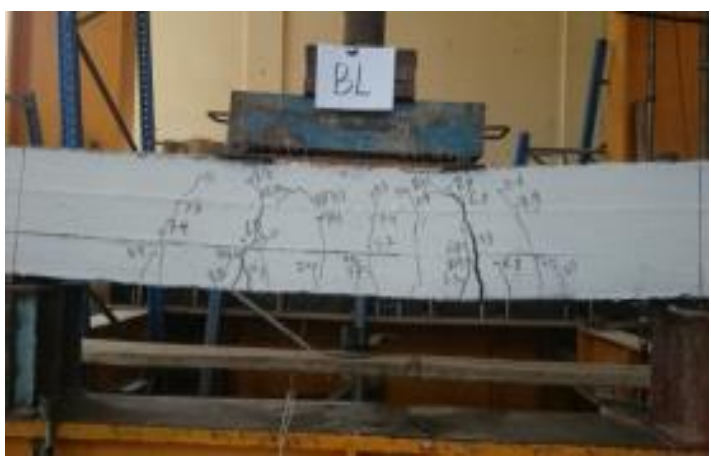

Fig. (32): Failure mode for the spliced beam BL
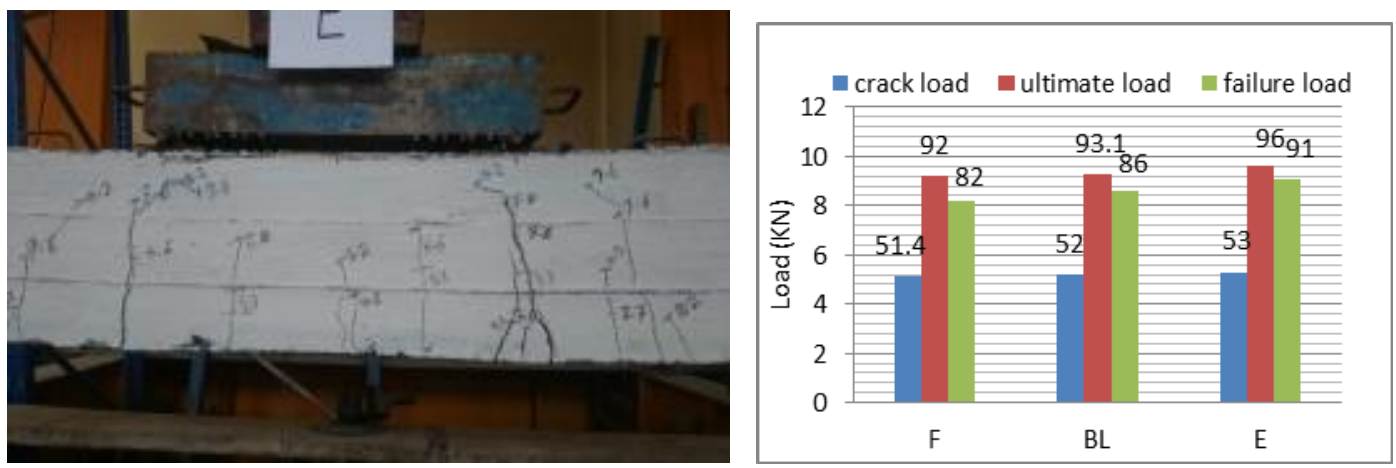

Fig. (33): Failure mode for the spliced beam E (splice spacing $=100 \mathrm{~mm}$ ).

Fig.(34): Comparison of the cracking, ultimate and failure loads for the spliced beams with variable stirrups spacing $(\mathrm{BL}, \mathrm{E} \& \mathrm{~F})$.

\section{Effect of the spliced length on the splicing behaviour}

Fig. (5,10\&11) indicate the structural details of the beams (BL, H \& G) with different spliced lengths (55Ø, 45Ø $\& 35 \varnothing$ respectively). At the same loading level, the splicing length inversely proportional to the beam deflection value. As the splicing length within the beam decreased from (55Ø) to (45Ø) and (35Ø), the ductility decreased by $(14 \%)$ and $(19 \%)$ respectively, also the initial stiffness at the linear stage decreased by $(28 \%)$ and $(51 \%)$ respectively as shown in Fig. (35).

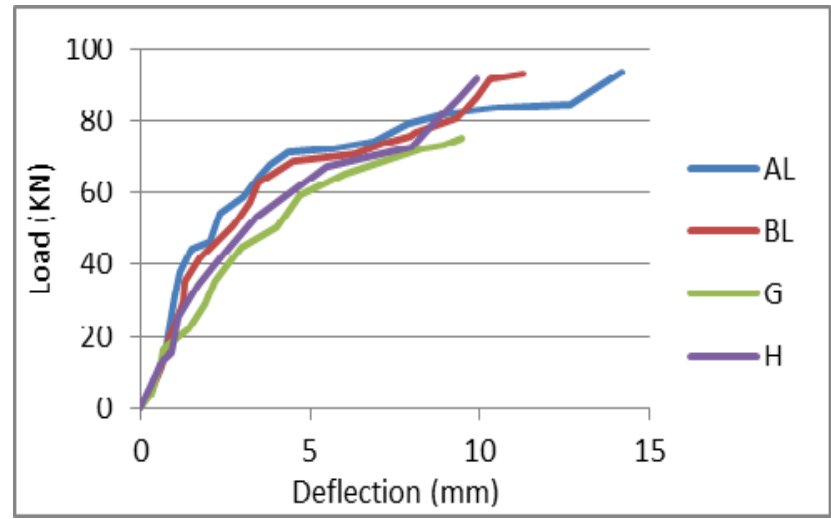

Fig. (35): Load-Deflection behavior for the spliced beams (BL, G \& H)

with different splicing lengths Fig.(36, 37 \& 38) show the crack patterns and failure modes of the tested beams. It was noted that, for the small bar sizes, decreasing the splicing length didn't affect the failure mode; however it decreased the flexural capacity of the beam. The flexure failures occurred outside the splicing zone. As the splice length decreased from (55Ø) to (45Ø) and (35Ø), the flexural strength decreased by $(1.8 \%)$ and $(13 \%)$ respectively as shown in Fig.(39), this satisfied the splicing tension length (55Ø) determined by the ECP specifications. 

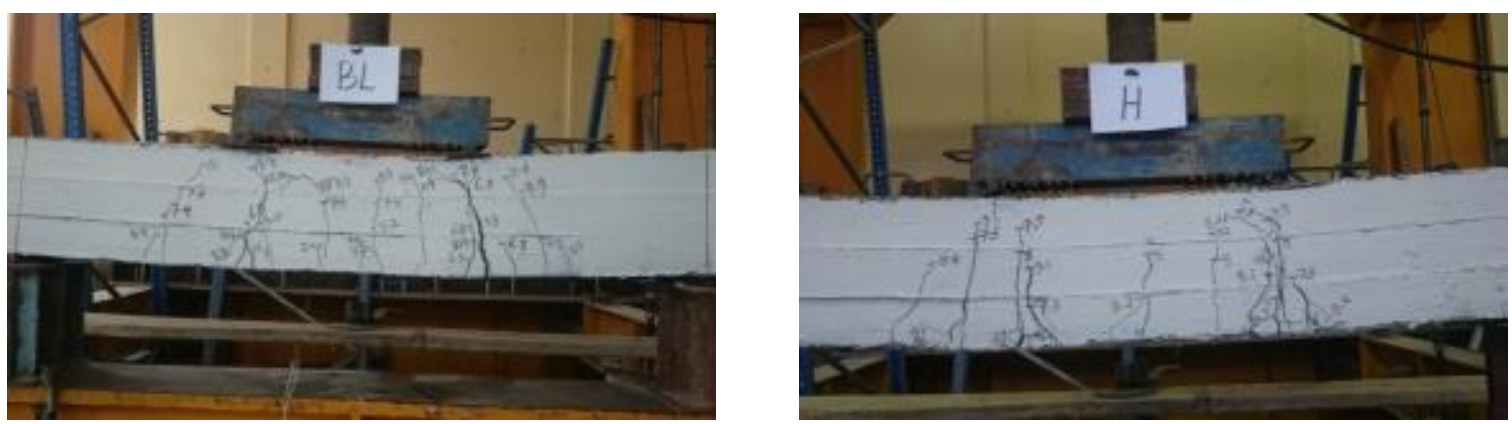

Fig. (36): Failure mode for the spliced beam BL $(\mathrm{Ls}=55 \varnothing)$

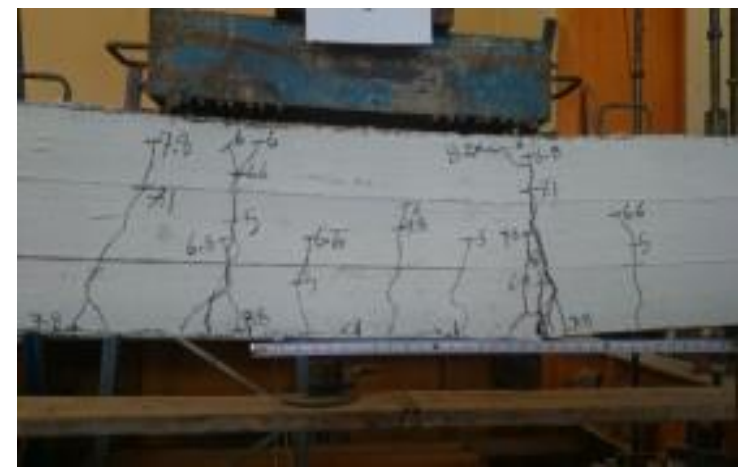

Fig(38): Failure mode for the spliced beam $G$ $\left(\mathrm{L}_{\mathrm{s}}=35 \varnothing\right)$.
Fig. (37): Failure mode for the spliced beam $\mathrm{H}$ $(\mathrm{Ls}=45 \varnothing)$.

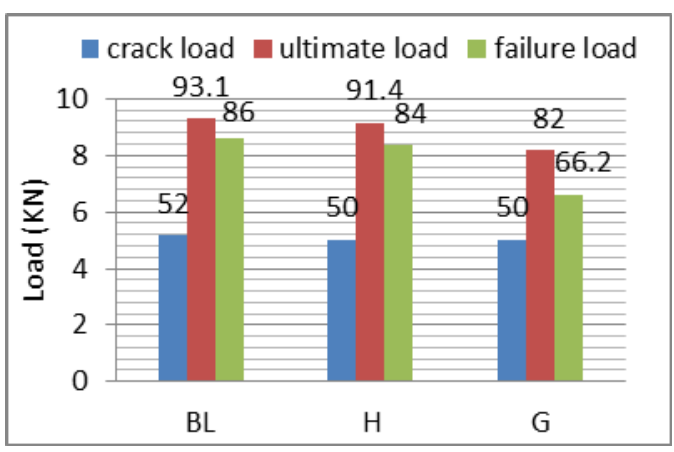

Fig. (39): Comparison of the cracking, ultimate and failure loads for the spliced beams with Variable splicing lengths (BL, $H \&$ G).

\section{E. Effect of the concrete cover depth on the splicing behavior}

Fig. $(5,12 \& 13)$ indicate the structural details of the beams (I, BL \& J) with different depths of concrete cover at tension zone $(10,20 \& 40 \mathrm{~mm})$ respectively. It's observed that the ductility tends to be greater for the deeper stirrups beam, which have the smaller concrete cover. As the bottom concrete cover decreased from $(40 \mathrm{~mm})$ to $(20 \mathrm{~mm})$ and $(10 \mathrm{~mm})$, i.e. increasing the depth of the stirrups, the resulted ductility increased by $(1 \%)$ and $(9 \%)$ respectively, and the initial stiffness of the beam decreased in both cases by about (50\%) as shown in Fig. (40).

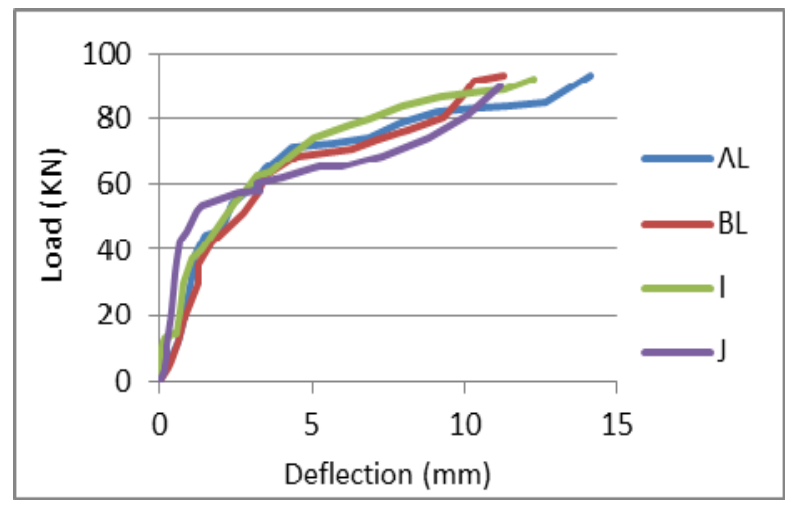

Fig. (40): Load-Deflection behavior for the spliced beams (BL, I \& J) with different depths of bottom concrete covers

It's observed from Fig. (41, 42 \& 43) that the failure modes of the tested beams (I, BL \& J) were almost the same outside the splicing zone and below the loading points, however the beam I (bot. cover $=10 \mathrm{~mm}$ ) exhibited a crushing of its thin concrete cover while failing. As the concrete cover depth increased from $(20 \mathrm{~mm})$ to $(40 \mathrm{~mm})$, the resulted flexural strength of the beam decreased by (3\%) as shown in Fig.(44), because the excessive cover reduced the moment arm (d), i.e. the depth between the compression and tension forces within the beam section. 


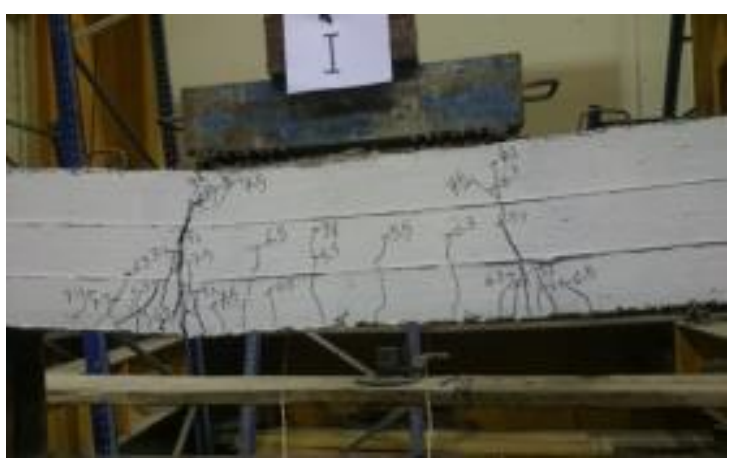

Fig. (41): Failure mode for the spliced beam I (bottom cover $=10 \mathrm{~mm}$ ).

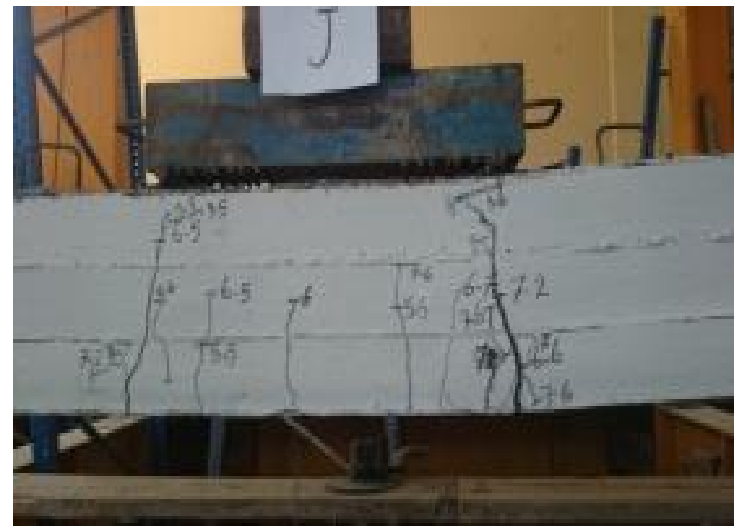

Fig. (43): Failure mode for the spliced beam J (bottom cover $=40 \mathrm{~mm}$ ).

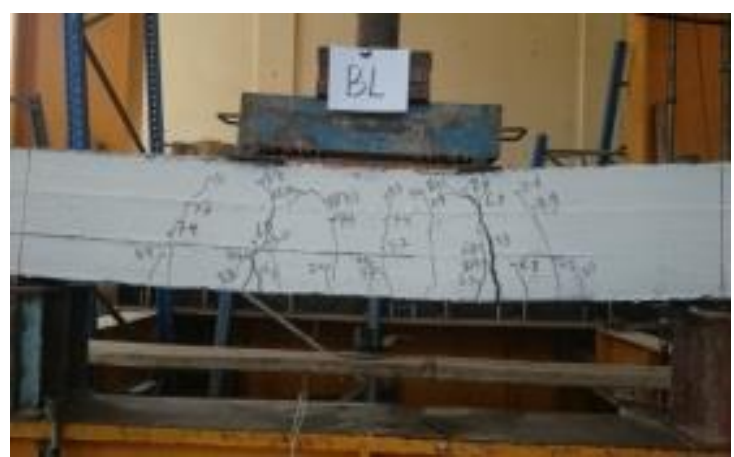

Fig. (42): Failure mode for the spliced beam BL (bottom cover $=20 \mathrm{~mm}$ ).

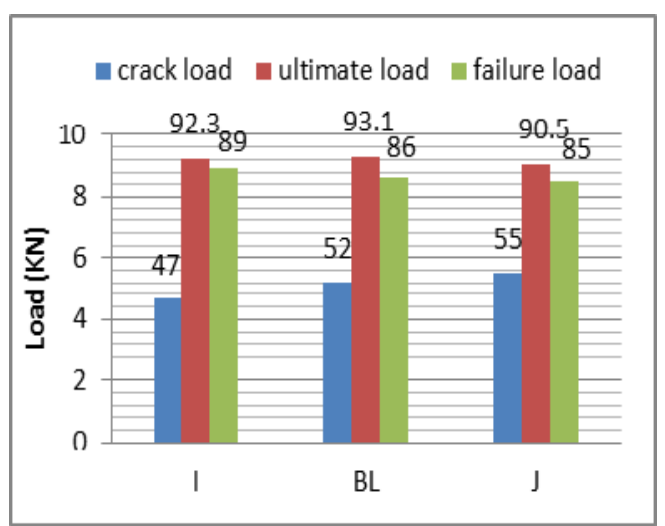

Fig.(44): Comparison of the cracking, ultimate and failure loads for the spliced beams with bottom cover depths (BL, I \& J).

\section{Splicing Bond Strength Calculations}

According to the (ACI committee 318), calculating the strength of the splicing bond between the reinforcing bars and the surrounding concrete depends on the stress of the reinforcing bar $\left(f_{\mathrm{s}}\right)$ as indicated in Eq. (1). Eq. (2) indicates the formula of the average bond stress $\left(U_{\text {test }}\right)$ in order to calculate the normalized bond strength in Eq. (3):

- Maximum bar stress:

- Average bond stress:

- Normalized bond ultimate stress

$$
\begin{aligned}
& f_{\mathrm{s}}=\mathrm{E}_{\mathrm{s}} * \text { Max steel strain } \\
& \begin{aligned}
\mathrm{U}_{\text {test }} & =f_{\mathrm{s}} * \mathrm{~d}_{\mathrm{b}} / 4 \mathrm{~L}_{\mathrm{s}} \\
& =\mathrm{U}_{\text {test }} / \sqrt{ } \mathrm{f}_{\mathrm{cu}}
\end{aligned}
\end{aligned}
$$

ACI code, while calculating the bond stress, takes into account the properties of both the concrete as well as the reinforcing steel bars which both are the two partners of the relationship; so that it is fair to obtain precisely the resulted bond stresses. Splicing bond strength calculations of the tested beams are indicated in table (III). However, on the other hand, ECP code considers only the properties of the steel bars only. 
TABLE IIIII. EXPERIMENTAL RESULTS FOR THE SPLICING BOND STRENGTH OF THE TESTED BEAMS

\begin{tabular}{|c|c|c|c|c|}
\hline Beam & $\begin{array}{c}\text { Max } \\
\text { Steel Strain }\left(\mu_{\text {str }}\right)\end{array}$ & $\begin{array}{c}\text { Measured } \\
\text { Steel Stress } \\
\left(f_{\mathrm{s}}\right)(\mathrm{Mpa})\end{array}$ & $\begin{array}{c}\text { Avg.Bond Stress by } \\
\text { ACI code } \\
f_{b}(\mathrm{Mpa})\end{array}$ & $\begin{array}{c}\text { normalized bond } \\
\text { ultimate stress by ACI } \\
\text { code(Mpa) }\end{array}$ \\
\hline BN & 1475 & 295 & 1.34 & 0.27 \\
\hline BL & 1548 & 310 & 1.41 & 0.28 \\
\hline C & 1435 & 287 & 1.30 & 0.26 \\
\hline D & 1295 & 259 & 1.18 & 0.24 \\
\hline E & 1725 & 345 & 1.57 & 0.31 \\
\hline F & 1233 & 247 & 1.12 & 0.22 \\
\hline G & 1396 & 279 & 1.99 & 0.40 \\
\hline H & 1411 & 282 & 1.57 & 0.31 \\
\hline I & 1388 & 278 & 1.26 & 0.25 \\
\hline J & 1626 & 325 & 1.48 & 0.30 \\
\hline
\end{tabular}

From the shown results, it is noted that, the normalized bond stress decreased by (7\%) and (16\%) in case of increasing the spliced bar diameter from $(10 \mathrm{~mm})$ to $(16 \mathrm{~mm})$ and $(22 \mathrm{~mm})$ respectively, which agree with ACI, that the bond strength is greater for smaller bar sizes which are preferable in use. Decreasing the stirrups spacing from $(200 \mathrm{~mm})$ to $(150 \mathrm{~mm})$ and $(100 \mathrm{~mm})$, increased the normalized bond strength by $(25 \%)$ and $(40 \%)$ respectively.That Agreed with ACI, which state that decreasing the stirrups spacing in the splicing zone, confines the spliced bars and increases the required force for the bond failure; thus increases the bond strength of the splicing. Reducing the splicing length from $(55 \phi)$ to $(45 \phi)$ and $(35 \phi)$, increased the normalized bond strength by (11\%) and (41\%) respectively. As the concrete cover depth increased the bond strength increased, however this relation is not linear, as increasing the concrete cover at tension zone from $(10 \mathrm{~mm})$ to $(20 \mathrm{~mm})$ and $(40 \mathrm{~mm})$, the normalized bond strength increased by $(11 \%)$ and $(17 \%)$ respectively.

\section{Conclusions}

Based on the analysis of experimental test results, it can be concluded that

1. NWC is stiffer than LWC, while LWC is more ductile. The cracks and the failure of the non-spliced beams occurred at the mid span where the maximum tension zone, while in the spliced beams the failure occurred outside the splicing zone due to expanding of the cracks vertically till failure.

2. LWC has a good performance for the tension lap splice and its splicing behavior approximates that of NWC regarding the ductility and flexural strength, however differs, regarding the stiffness.

3. The splicing decreased the ductility of the NWC and LWC beams by about (20\%), while decreased the initial stiffness of the NWC and LWC beams by (7\%) and (16\%) respectively.

4. The splice bar size inversely proportional to the resulted ductility, while directly proportional to the stiffness and flexural capacity. As increasing the spliced bar size within a beam from $(10 \mathrm{~mm})$ to $(16 \mathrm{~mm})$ and $(22 \mathrm{~mm})$ the ductility decreased by $(40 \%)$ in the two cases and increased the initial stiffness and flexural strength by $(60 \%)$ and $(151 \%)$ and $(86 \%)$ and $(160 \%)$ respectively.

5. Increasing the transverse reinforcement, i.e. reducing the stirrups spacing within a beam, from $(200 \mathrm{~mm})$ to $(150 \mathrm{~mm})$ and $(100 \mathrm{~mm})$ increased its resulted ductility by $(4 \%)$ and $(9 \%)$ respectively, and the initial stiffness by $(15 \%)$ and $(44 \%)$ respectively, while its flexural strength slightly increased by only $(1.2 \%)$ and $(4.2 \%)$ respectively.

6. Decreasing the splicing length from (55Ø) to $(45 \varnothing)$ and $(35 \varnothing)$ in the beam reinforcement, caused a decreasing its ductility by (14\%) and (19\%) respectively and its initial stiffness by $(28 \%)$ and $(51 \%)$ respectively. Also the flexure strength decreased by $(1.8 \%)$ and (13\%) respectively, which reflects the success of the equation developed by the ECP code determining the splicing length to (55Ø) in the case of tension splicing.

7. The bottom concrete cover depth commonly used $(20 \mathrm{~mm})$ is the most efficient and preferable to use, providing the beam with the most accessible strength, while the extra concrete cover $(40 \mathrm{~mm})$ did not provide an additional strength due to reducing the moment arm (d) within the beam section which consequently decreasing its flexural capacity. 


\section{REFERENCES}

[1] A. Kan, and R. Demirbog, "A novel material for lightweight concrete production," Cement \& Concrete Composites., vol. 31, pp. 489495, May. 2009.

[2] E. Sancak, O. Simsek, and A. Apay, “A comparative study on the bond performance between rebar and structural lightweight pumice concrete with/without admixture," International Journal of the Physical Sciences., vol. 6(14), pp. 3437-3454, July. 2011.

[3] M. Pecce, F. Ceroni, F. Bibbo, and S. Acierno,"Steel-concrete bond behaviour of lightweight concrete with expanded polystyrene (EPS)," Materials and Structures., vol. 48, pp. 139-152, 2015.

[4] I. Topcu, and T. Uygunoglu,"Effect of aggregate type on properties of hardened self-consolidating lightweight concrete (SCLC)," Construction and Building Material., vol. 24, pp. 1286-1295, January. 2010.

[5] X. Tan, "Influence of high temperature on the residual physical and mechanical properties of foamed concrete," Construction \& Building materials., vol. 135, pp. 203-211, 2017.

[6] E. Canbay, and R. Frosch,"Bond strength of lap-spliced bars,” ACI Structural Journal., vol. 102(4), pp. 605-614, 2005.

[7] A. Hosny,"Bond bahavior of high performance reinforcing bars for concrete structures," M. Eng. Thesis,Faculty of Engineering, North Carolina State University, USA, 2007.

[8] W. Tang, Y. Lo, and A. Nadeem,"Mechanical and drying shrinkage properties of structural-graded polystyrene aggregate concrete," Cement \& Concrete Composites., vol. 30, pp. 403-409, January. 2008.

[9] M. Omnia,"Effect of tension lap splice position on the behavior of lightweight concrete beams," M. Eng. Thesis, Faculty of Engineering, Ain Shams University, Cairo, Egypt, 2008.

[10] ACI committee 408R, Bond and Development of Straight Reinforcing Bars in Tension, (Reapproved 2012), American Concrete Institute, Farmington Hills, Michigan, USA, 2003.

[11] A. Azizinamini, M. Chisala, J. Roller, and S. Ghosh,“Tension Development Length of Reinforcing Bars Embedded in High-Strength Concrete," Engineering Structures., vol. 17(7), pp. 512-522, 1995.

[12] ACI committee 318, Building Code Requirements for Structural Concrete and Commentary, American Concrete Institute, Farmington Hills, Michigan, USA,2008.

[13] The Egyption Code for the Design and Construction of Reinforced Concrete Structures, ECP Std. 203-2018, Housing and Building Research Center, Giza, Egypt, 2001.

[14] A. El-Azab, and H.M. Mohamed, "Effect of tension lap splice on the behavior of high strength concrete (HSC) beams," Housing and Building National Research Center Journa., vol. 10, pp. 287-297, January. 2014.

[15] A. Kan, and R. Demirbog,"Effect of cement and EPS beads ratios on compressive strength and density of lightweight concrete," Indian J Eng Mater Sci., vol. 14, pp. 158-62, 2007.

[16] E. Sancak, O. Simsek, and A. Apay,"A comparative study on the bond performance between rebar and structural lightweight pumice concrete with/without admixture," International Journal of the Physical Sciences., vol. 6(14), pp. 3437-3454, 2007. 